\title{
Frequency of caseous lymphadenitis (CLA) in sheep slaughtered in an abattoir in Tabriz: comparison of bacterial culture and pathological study
}

\author{
Fereydon Rezazadeh Zavoshti • \\ Amir Babak Sioofy Khoojine • Javad Ashrafi Helan • \\ Belal Hassanzadeh • Ali Akbar Heydari
}

Received: 8 July 2010 / Accepted: 7 December 2010 / Published online: 6 January 2011

(C) The Author(s) 2011. This article is published with open access at Springerlink.com

\begin{abstract}
From January to February 2008, 468 sheep carcasses (335 male and 133 female) in a Khosroshahr (suburb of Tabriz, East Azerbaijan province, Iran) abattoir were randomly selected for inspection. The aim of the study was to estimate the frequency of caseous lymphadenitis (CLA) in sheep and to compare the results of bacterial cultures and histopathology of suspected cases. The mean age of the population was 2.5 years. One hundred ninetyseven cases containing $153(77.7 \%)$ males and $44(22.3 \%)$ females had prominent enlargement of one of the lymph nodes (i.e., prescapular, prefemoral, inguinal, supramammary, or midiastinal); these were removed with the surrounding tissue for further evaluation. For confirmed diagnosis of CLA, samples were sent for microbiology and pathology analysis. Standard bacteriological culture methods for isolation of Corynebacterium pseudotuberculosis and tissue preparations
\end{abstract}

F. R. Zavoshti $(\bowtie)$

Department of Clinical Sciences, Faculty of Veterinary Medicine, University of Tabriz,

Tabriz, Iran

e-mail: f_rezazadeh@tabrizu.ac.ir

A. B. S. Khoojine · J. A. Helan

Department of Pathobiology, Faculty of veterinary Medicine, University of Tabriz,

Tabriz, Iran

B. Hassanzadeh

Department of Basic Science, Faculty of Veterinary Medicine, Ferdowsi University of Mashhad,

Mashhad, Iran

A. A. Heydari

Department of Statistics, Faculty of Mathematical Sciences, University of Tabriz,

Tabriz, Iran for histopathological sections were performed. To evaluate the effect of age on the frequency of CLA, animals were categorized in four groups: under 1, 1-2, 2-3, and over 3 years of age. Based on the results, in $59(12.60 \%)$ carcasses C. pseudotuberculosis was isolated, and in 94 (20.08\%) of the cases histopathological studies revealed pathognomonic signs (lamellated exudates or onion ring) of CLA. The frequency of CLA based on bacteriological culture was $12.60 \%$ and on histopathological study $20.08 \%$. In 37 (18.8\%) of the carcasses, both bacteriological and histopathological studies confirmed CLA. The frequency of CLA following microscopic examination (20.08\%) presented a more precise diagnosis compared to bacteriological culture $(12.60 \%)$ and macroscopic evaluation of the lymph nodes $(P<0.05)$. Furthermore, there was a positive correlation rate between the bacteriological culture and histopathological study $(r=0.196, P=0.006)$. The prescapular lymph node had the highest infection rate with $54(1.70 \pm 0.97)$ and supramammary lymph node had the lowest with two $(0.07 \pm 0.41)(P<0.05)$. There was an increase in CLA detection with increasing age $(P<0.05)$, the mean age of animals with a positive CLA test were 2.92 years and in the oldest age group 31 (47\%) cases had the highest infection.

Keywords Caseous lymphadenitis · Sheep · Frequency Tabriz · Iran

\section{Introduction}

Caseous lymphadenitis (CLA) was reported for the first time in the world by Preisz and Guinard in 1891 and Nocard in 1896 and in Iran by Afnan and his colleagues in 
1964 (Hosseinzadeh et al. 1996; Baird and Fontaine 2007; Fontaine and Baird 2008). The disease was recognized in sheep in Britain in 1991 and in the Netherlands in 1978 (Dercksen et al. 2000). The agent was isolated in Venezuela in 1962 (Chirino-Zarraga et al. 2006). The agent of CLA is a gram-positive actinomytes called Corynebacterium pseudotuberculosis but other agents such as Staphylococcus spp., Streptococcus spp., Bacillus spp., Micrococcus spp., Antrobacter spp., Aeromonas spp., Morexilla spp., and Pasturella spp. have also been isolated from infected lymph nodes (Hosseinzadeh et al. 1996; Fontaine and Baird 2008; Radostits et al. 2007; Richard et al. 1979). The old name of the bacterium was Corynebacterium ovis (Ghadimi 1993; Smith 2002). The presence of CLA had been recognized for over 100 years (Fontaine and Baird 2008) and has been reported in infected sheep in Australia, New Zealand, South Africa, Middle east, North and South America, England, and in most parts of Northern and Southern Europe (Ghadimi 1993; Dercksen et al. 2000; Fontaine and Baird 2008; Fontaine et al. 2006; O'Reilly et al. 2008; Radostits et al. 2007; Smith 2002). The disease has been reported in other animals such as horse, lama, alpaca, buffalo, deer, and camels (Ghadimi 1993; Braga 2007; Fontaine and Baird 2008; Smith 2002). Occasionally, abortions have been reported due to C. pseudotuberculosis in sheep (Fontaine and Baird 2008). According to one study, the economic loss due to the disease in Australia was 17 million Australian dollars (Cetinkaya et al. 2002). Contamination of meat in slaughterhouses in the presence of an infectious agent in adult sheep is $3-5 \%$ and $0.02-0.03 \%$ in lambs (Hodgson et al. 1999; Radostits et al. 2007). The source of the infection is sheep that have lacerated superficial lymph node abscesses resulting in the agent being disseminated to other animals (O'Reilly et al. 2008; Sunil et al. 2008). Nasal and oral discharge is very important in the transmission of the disease in sheep with abscess in the lungs due to C. pseudotuberculosis (Ellis et al. 1987; Fontaine and Baird 2008; O'Reilly et al. 2008; Radostits et al. 2007; Sunil et al. 2008). The mediastinal lymph nodes and lungs are the most visceral organs that are infected with C. pseudotuberculosis, but other internal organs can present with the abscess (Ghadimi 1993; Binns et al. 2007; Fontaine and Baird 2008).

Phospholipidase D, a $31.5-\mathrm{kDa}$ molecule, is the specific exotoxin of C. pseudotuberculosis; it causes the lysis of the sphingomyelin and the transfer of the agent which causes plasma to exit from the blood vessels into the lymph nodes (Radostits et al. 2007; Smith 2002). Abscesses may form in $60-80 \%$ of infected lymph nodes and the agent can persist against the phagocytic action of the immune system due to the high lipid content in their cell wall, hence making it an intracellular parasite (Ghadimi 1993; Fontaine and Baird 2008; Hodgson et al. 1999; Radostits et al. 2007; Smith 2002). Capsule formation causes the organism to establish in the body (Fontaine and Baird 2008). Cellular immunity is more important than humoral immunity against CLA (Prescott et al. 2002). One of the characteristics of $C$. pseudotuberculosis is that it is reactive in old abscesses and can cause a relapse of the disease and clinical signs in the animal (Fontaine and Baird 2008). The clinical signs of CLA are prominent enlargement of superficial lymph nodes such as submandibular, prescapular, prefemoral, supramammary, popliteal, or in visceral organs such as lungs (Binns et al. 2007; Dercksen et al. 2000; Fontaine and Baird 2008; Radostits et al. 2007; Smith 2002). The postmortem signs are green yellowish exudates from infected superficial lymph nodes in animals (Radostits et al. 2007). In the primary stage, the pus in the lymph nodes is smooth and in the progressive stages is lamellate (onion skin or onion ring), a pathognomonic signs of CLA (Fontaine and Baird 2008; Radostits et al. 2007). The standard bacterial culture from intact lymph nodes and/or histopathological study from lymph nodes fixed in formalin is used to identify CLA (Radostits et al. 2007; Smith 2002).

\section{Material and methods}

From January to February 2008, 468 sheep carcasses (335 male and 133 female) in a Khosroshahr (suburb of Tabriz, East Azerbaijan province, Iran) abattoir were randomly selected for inspection. The aim of the study was to estimate the frequency of CLA in sheep and to compare the results of bacterial cultures and histopathology of suspected cases. The samples were taken from the carcasses that had prominent enlargement of at least one of the submandibular, prescapular, prefemoral, supramammary, popliteal, or visceral organs such as lungs; the lymph capsule with the surrounding tissue was excised (care was taken not to cut any of the infected surfaces) and sent in an ice container at $4^{\circ} \mathrm{C}$ to the microbiology laboratory. The surrounding tissue was cut and removed and the capsules of lymph nodes were burned and culture of pus performed in brain heart infusion broth for isolation of the C. pseudotuberculosis. One hundred microlitres of culture were transferred to blood agar enriched with sheep blood and incubated at $37^{\circ} \mathrm{C}$. The resulting single colonies were purified and studied for their morphology. The suspected Coccobacillus to C. pseudotuberculosis was examined using biochemical tests. Single colonies with the same biochemical test profile as C. pseudotuberculosis were identified and sampled (Ghadimi 1993). In all suspected cases, for histopathological study the lymph nodes were divided into two slices in the sagittal plane and transferred for fixation in $10 \%$ formalin. After $24-48 \mathrm{~h}$ the formalin solution was changed and the lymph nodes were inspected for size, color, numbers, consistency of pus, and macroscopic 


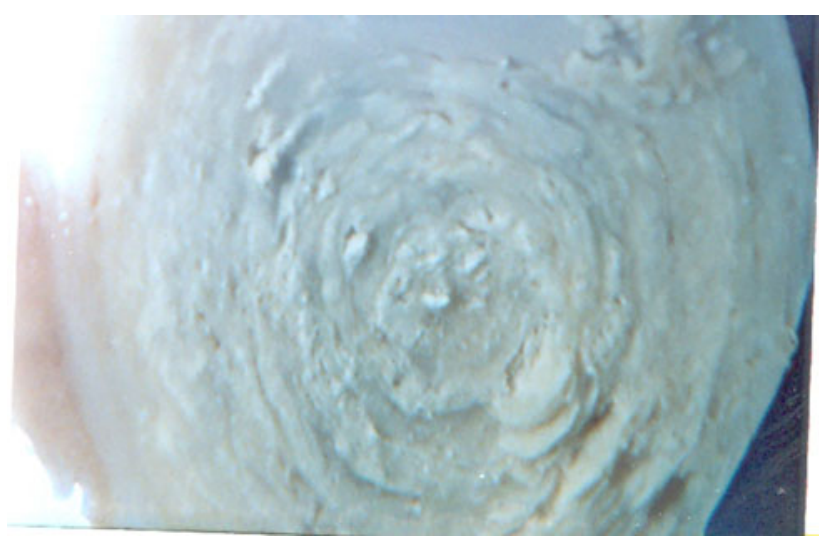

Fig. 1 Cross-sectional view of infected lymph node (mediastinal) to CLA in the present study shows the calcium granules that deposited and had rule to formation of lamellate in abscess

view of exudates (lamellate or onion rings). Tissue processing was undertaken using a tissue processor, (Leica, Jung Histokinette 200, Germany) and sectioning of the tissue using a sliding microtome (Leica, Jung Histocuts, Germany). Sections were stained manually with hematoxylin and eosin (H \& E). Microscopic evaluation of tissue was performed using an Olympus microscope (model CH36 RF200, Japan). Photomicrographs were taken with a digital camera (DP12, U-TVO.5XC-2, and Japan) (Luna 1968). Pathognomonic lesion (lamellate, onion, or onion ring) were used for diagnosis. The onion ring signs (centripetal circles) viewed under macroscopic or microscopic examination (Figs. 1, 2, and 3) or from isolation of $C$. pseudotuberculosis in the bacteriological study was the basis of CLA determination in sheep. If the exudate circles were not seen in histopathological examination, it was not recognized as CLA in our study. Age determination was based on dental eruption and change between milk and permanent teeth.

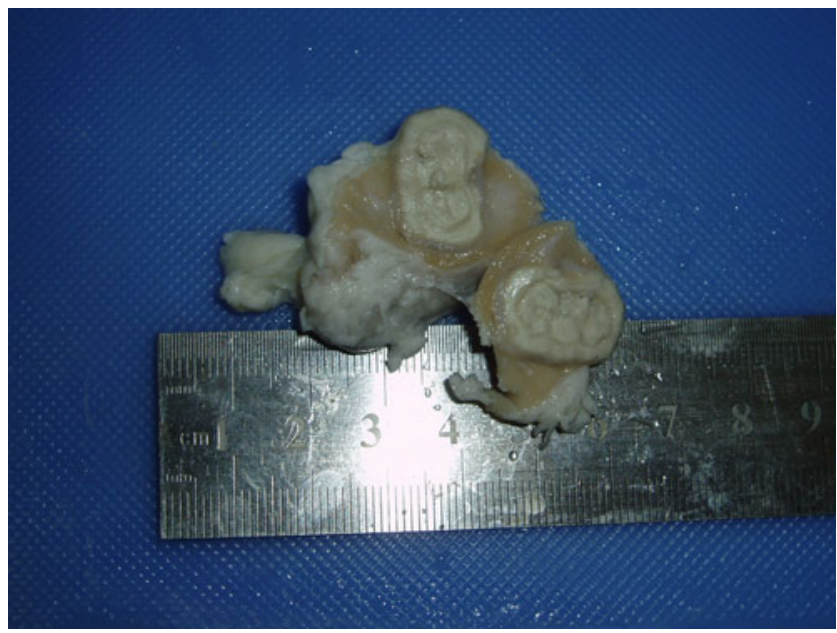

Fig. 2 Prescapular lymph node of a sheep infected with Corynebacterium pseudotuberculosis shows the centripetal circles of exudates. Note the connective tissue capsules that surrounded the exudates

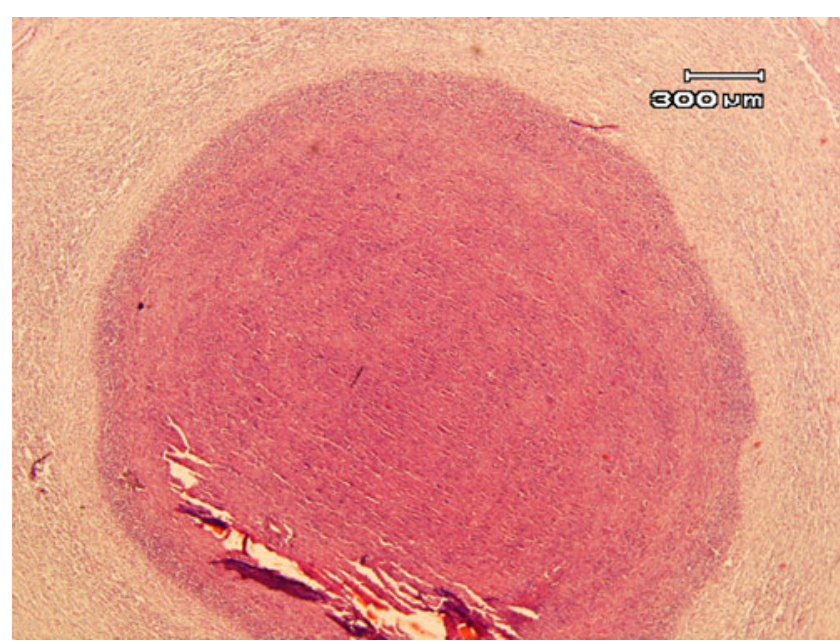

Fig. 3 Microscopic view of prescapular lymph node infected with $C$. pseudotuberculosis (CLA) H \& E ×40)

Animals were grouped into four categories (under 1, 1-2, 2-3, and $>3$ years) (Hosseinzadeh et al. 1996; Dyce et al. 1995). Statistical analysis of the data was done using SPSS (version 16) software.

\section{Results}

From the 468 sheep carcasses randomly selected, 197 cases were suspected to have CLA with signs of prominent enlargement in one of the lymph nodes. In 59 cases (12.60\%) pure C. pseudotuberculosis was isolated. In 94 (20.8\%) cases histopathological study represented pathognomonic signs of CLA (onion ring signs). The average age of the population was 2.92 years, and there was an increase in the frequency of CLA with age $(P<0.05)$. From 59 cases that isolated $C$. pseudotuberculosis, 40 were male and $19(4.05 \%)$ were female, this did not represent a statistical difference $(P>0.05)$. Tables 1,2 and 3 and Figs. 1, 2, and 3 show details of results in the present study. One hundred twelve $(56.9 \%)$ cases did not result in any isolated microorganisms. In 12 (2.56\%) cases Staphylococcus

Table 1 Frequency of CLA based on microbiology isolation with sex in present study

\begin{tabular}{lccc}
\hline Sex & $\begin{array}{l}\text { Total number } \\
\text { of inspected } \\
\text { carcasses }\end{array}$ & $\begin{array}{l}\text { Percentage and number } \\
\text { of cases with isolation } \\
\text { of Corynebacterium } \\
\text { pseudotuberculosis }\end{array}$ & \\
\hline Male* & 335 & $40(8.54 \%)$ & $(P>0.05)$ \\
Female & 133 & $19(4.05 \%)$ & \\
Summation & 468 & 59 &
\end{tabular}

*In 95\% standard level (significance, 5\%) did not have statistical differences between both sexes $(P>0.05)$ 
Table 2 Results of isolation of Corynebacterium pseudotuberculosis in four groups in both sexes

\begin{tabular}{|c|c|c|c|c|c|c|}
\hline Age group & Under 1 year & $1-2$ years & $2-3$ years & Above 3 years $^{\mathrm{a}}$ & Summation & Total \\
\hline The carcasses inspected & $\begin{array}{l}\text { Male } 80 \\
\text { Female } 3\end{array}$ & $\begin{array}{l}\text { M. } 179 \\
\text { F. } 11\end{array}$ & $\begin{array}{l}\text { M. } 21 \\
\text { F. } 18\end{array}$ & $\begin{array}{l}\text { M. } 55 \\
\text { F. } 101\end{array}$ & $\begin{array}{l}\text { Male } 338 \\
\text { Female } 133\end{array}$ & 468 \\
\hline $\begin{array}{l}\text { Number and } \\
\text { percentage of positive }\end{array}$ & $\begin{array}{l}4(6.7 \%) \\
0(0 \%)\end{array}$ & $\begin{array}{l}17(28.8 \%) \\
2(3.38 \%)\end{array}$ & $\begin{array}{l}4(6.7 \%) \\
1(1.69 \%)\end{array}$ & $\begin{array}{l}14(23.7 \%) \\
17(28.8 \%)\end{array}$ & $\begin{array}{l}41(69.4 \%) \\
19(32.2 \%)\end{array}$ & $59(100 \%)$ \\
\hline
\end{tabular}

$M$. male, $F$. female

${ }^{\text {a }}$ Statistical differences with other groups $(P<0.05)$

aureus, in four $(0.85 \%)$ cases Bacillus, and in three $(0.64 \%)$ cases both pure C. pseudotuberculosis and Staphylococcus aureus were isolated in microbiology. Macroscopic examination of prescapular lymph nodes represented 36 cases with lamellate exudates, but the microscopic study showed that 66 $(61.68 \%)$ of the samples had CLA signs, resulting in the highest frequency of CLA; a statistical difference with infection compared with other lymph nodes $(P<0.05)$. In all cases studied the microscopic examination gave a more precise diagnosis compared with the macroscopic examination $(P<0.05)$. Thirty-seven cases out of 197 had both microbiology and histopathology results that identified CLA.

\section{Discussion}

CLA causes chronic emaciation, contamination of meat, loss of health, and reduction of wool production in sheep. Due to the slow progression of CLA and the little information and data on the disease, most countries do not pay attention to its eradication and prevention (Baird and Fontaine 2007; Fontaine and Baird 2008; O'Reilly et al. 2008; Ural et al. 2008). This study on CLA was undertaken in an abattoir because the visceral form of CLA can only be recognized after killing the animal (Hosseinzadeh et al. 1996; Zahraei and Shayeg 2007; Cetinkaya et al. 2002; Radostits et al. 2007). In a large-scale study in sheep in Australia, the prevalence of CLA was 26\% (Paton et al. 2003, 1996; Radostits et al. 2007). Some other studies and references estimated the CLA rates between 5\% and 10\% (Smith 2002). In an abattoir study in Turkey, the prevalence of CLA was $3.5 \%$ (Cetinkaya et al. 2002). In the present study, the frequency of CLA based on bacteriological culture was $12.60 \%$ and on histopathology was $20.08 \%$.
The defense mechanism of $C$. pseudotuberculosis prevents the organism from being isolated in all bacteriology cultures; therefore, we used both identification methods (culture and histopathology) to identify CLA (Radostits et al. 2007; Sunil et al. 2008). This may be the reason why the agent was not isolated from 112 carcasses. Furthermore, the abscess is formed in only $60-80 \%$ of infected animals, and it is important that we see the onion-skin or lamellate shape in the abscess in histopathology to identify CLA (Fontaine and Baird 2008; Jubb and Palmer 2007; Radostits et al. 2007). Furthermore, correlation rate between the bacteriological culture and histopathological study was positive $(r=0.196)$ and significant $(P=0.006)$. In $37(18.8 \%)$ carcasses, both bacteriological and histopathological studies confirmed CLA. These results are in agreement with previous studies (Hosseinzadeh et al. 1996; Fontaine and Baird 2008; Hodgson et al. 1999; Radostits et al. 2007; Smith 2002). Reaction to other viruses can cause lymphadenitis in some animals (Ellis and DeMartini 1985; Ellis et al. 1987; Fulton et al. 2006; Yirrell et al. 1991), which might explain why we did not obtain the bacteria in all cases in this study. The microbiology isolated $12(2.56 \%)$ suspected Staphylococcus aureus cases, four $(0.85 \%)$ Bacillus cases, and in three $(0.64 \%)$ cases of both pure C. pseudotuberculosis, and Staphylococcus aureus, these results are in agreement with previous studies (Hosseinzadeh et al. 1996; Fontaine and Baird 2008; Radostits et al. 2007; Richard et al. 1979). The prescapular lymph node had the highest infection rate compared with other lymph nodes and this finding is the same with other studies (Hosseinzadeh et al. 1996; O'Reilly et al. 2008; Sunil et al. 2008). The mediastinal lymph node had the second highest rate of infection for C. pseudotuberculosis, illustrating the importance of blood and air in the transmission of CLA (Binns et al. 2007; Fontaine and Baird 2008).

Table 3 The results of macroscopic and microscopic examination in suspected animals with CLA (some cases were infected with more than one lymph node)

\begin{tabular}{|c|c|c|c|c|c|c|}
\hline Lymph node & Prescapular & Prefemoral & Supramammary & Inguinal & Mediastinal & Summation \\
\hline Macroscopic examination & $36(60 \%)$ & $3(5 \%)$ & $2(3.3 \%)$ & $3(5 \%)$ & $16(26.7 \%)$ & $60(100 \%)$ \\
\hline Histopathology study ${ }^{a}$ & $66(61.68 \%)$ & $4(3.70 \%)$ & $3(2.8 \%)$ & $8(7.4 \%)$ & $26(24.07 \%)$ & $107(100 \%)$ \\
\hline
\end{tabular}

${ }^{\mathrm{a}}$ In all groups the histopathology had precisely more than macroscopic examination of suspected lymph nodes to CLA $(P<0.05)$ 
Our finding regarding the increase in CLA with increasing age is in agreement with Hosseinzadeh et al. and Radostits et al. (Hosseinzadeh et al. 1996; Arsenault et al. 2003; Radostits et al. 2007). In the present study, the oldest group ( $>3$ years of age) had the highest infection rate and was statistically different from the other groups. Based on these results and with this knowledge that we do not use vaccine against CLA in Iran, it seems that education of sheep owners, disinfection utilities in shearing sheep, and drug usage in the control of ectoparasites is very important in the prevention and control of CLA in this part of the country.

Acknowledgement We acknowledge the vice-chancellor of research at the University of Tabriz. The project number was 27/46463.

Open Access This article is distributed under the terms of the Creative Commons Attribution Noncommercial License which permits any noncommercial use, distribution, and reproduction in any medium, provided the original author(s) and source are credited.

\section{References}

Arsenault J, Girard C, Dubreuil P, Daignault D, Rene-Galarnequ J, Boisclair J, Simard C, Belanger D (2003) Prevalence of and carcass condemnation from maedi-visna, paratuberculoisis and caseous lymphadenitis in culled sheep from Quebec, Canada. Prev Vet Med 59:67-81

Baird GJ, Fontaine MC (2007) Corynebacterium pseudotuberculosis and its role in ovine caseous lymphadenitis. J Comp Pathol 137:179-210

Binns SH, Green LE, Bailey M (2007) Development and validation of an ELISA to detect antibodies to Corynebacterium pseudotuberculosis in ovine sera. Vet Microbiol 123:169-179

Braga WU (2007) Protection in alpacas against Corynebacterium pseudotuberculosis using different bacterial components. Vet Microbiol 119:297-303

Cetinkaya B, Karahan M, Atil E, Kalin R, De Baere T, Vaneechoutte M (2002) Identification of Corynebacterium pseudotuberculosis isolates from sheep and goat by PCR. Vet Microbiol 88:75-83

Chirino-Zarraga C, Scaramelli A, Rey-Valerion C (2006) Bacteriological characterization of Corynebacterium pseudotuberculosis in Venezuelan goat flocks. Small Rumin Res 65:170-175

Dercksen DP, Brinkhof JMA, Dekker-Nooren T, Van Maanen K, Bode CF, Baird G, Kamp EM (2000) A comparison of four serological tests for the diagnosis of caseous lymphadenitis in sheep and goats. Vet Microbiol 75:167-175

Dyce KM, Sack WO, Wensing CJG (1995) Textbook of veterinary anatomy. W. B. Saunders Company, Philadelphia, Chapter 25, pp. 607.

Ellis JA, DeMartini JC (1985) Immunomorphologic and morphometric changes in pulmonary lymph nodes of sheep with progressive pneumonia. Vet Pathol 22(1):32-41

Ellis TM, Sutherland SS, Wilkinson FC, Mercy AR, Paton MW (1987) The role of Corynebacterium pseudotuberculosis lung lesions in the transmission of this bacterium to other sheep. Aust Vet J 64(9):261-263
Fontaine MC, Baird GJ (2008) Caseous lymphadenitis. Small Rumin Res 76:42-48

Fontaine M, Baird G, Connor KM, Rudge K, Sales J, Donachie W (2006) Vaccination confers significant protection of sheep against infection with a virulent United Kingdom strain of Corynebacterium pseudotuberculosis. Vaccine 24:5986-5996

Fulton BE Jr, Portella M, Radke K (2006) Dissemination of bovine leukemia virus-infected cells from a newly infected sheep lymph node. J Virol 80(16):7873-7884

Ghadimi M (1993) Corynebacterium pseudotuberculosis and its pathogenic rules in man and animal. Research and Reconstruction 19:78-79

Hodgson ALM, Carter K, Tachdjian M, Krywult J, Corner LA, McColl M, Cameron A (1999) Efficacy of an ovine caseous lymphadenitis vaccine formulated using a genetically inactive form of the Corynebacterium pseudotuberculosis phospholipase D. Vaccine 17:802-808

Hosseinzadeh S, Haghkhah M, Zehtab K, Shekarforoush Sh (1996) The frequency of caseous lymphadenitis is sheep slaughtered in Shiraz abattoir. J Fac Vet Med, Univ of Tehran 51(1-2):81-88

Jubb, Kennedy, Palmer (2007) Pathology of domestic animals. In: Grant Maxie M. (ed) 5th edition. Elsevier, 292-294

Luna LG (1968) Manual of histologic staining methods of the armed forces institute of pathology, 3rd edn. McGraw- Hill Book Co, New York, pp 1-46

O'Reilly KM, Green LE, Malone FE, Medley GF (2008) Parameter estimation and simulations of a mathematical model of Corynebacterium pseudotuberculosis transmission in sheep. Prev Vet Med 83:242-259

Paton M, Rose I, Hart R, Sutherlan S, Mercy A, Ellis T (1996) Postshearing management affects the seroincidence of Corynebacterium pseudotuberculosis infection in sheep flocks. Prev Vet Med 26:275-284

Paton MW, Walker SB, Rose IR, Watt GF (2003) Prevalence of caseous lymphadenitis and usage of caseous lymphadenitis vaccines in sheep flocks. Aust Vet J 81(1-2):91-95

Prescott JF, Menzies PI, Hwang YT (2002) An interferon-gamma assay for diagnosis of Corynebacterium pseudotuberculosis infection in adult sheep from a research flock. Vet Microbiol 88:287-297

Radostits OM, Gay CC, Hinchcliff KW, Constable PD (2007) Veterinary medicine 10th edition. Saunders Elsevier, Philadelphia, pp 795-798

Richard Y, Fontaine M, Oudar J, Fontaine MP (1979) Contribution to an epidemiological study and the pathogenesis of caseous lymphadenitis of sheep. Comp Immunol Microbiol Infect Dis 2:125-148

Smith PB (2002) Large animal internal medicine, 3rd edition, Mosby, Inc., Missouri, pp 583-584 and 1078-1083

Sunil V, Menzies PI, Shewen PE, Prescott FF (2008) Performance of a whole blood interferon-gamma assay for detection and eradication of caseous lymphadenitis in sheep. Vet Microbiol 128:288-597

Ural K, Alic D, Haydardedeoglu AE, Cedden F, Guzel M, Ozyildiz Z, Cantekin Z (2008) Corynebacterium pseudotuberculosis infection in Saanen Kilis crossbred (white) goats in Ankara, Turkey and effective kanamycin treatment: a prospective, randomized double-blinded, placebo-controlled clinical trial. Small Rumin Res 77:84-88

Yirrell DL, Reid HW, Norval M, Entrican G, Miller HR (1991) Response of efferent lymph and popliteal lymph node to epidemiological infection of sheep with orf virus. Vet Immunol Immunopathol 28(3-4):219-235

Zahraei TS, Shayeg J (2007) Veterinary microbiology and microbial diseases (bacterial diseases), Translated 1st edition. Tehran University Press, Tehran, pp 29-39 